\title{
Inveja do gado: o fazendeiro como figura de poder e desejo entre os Karitiana
}

\section{Felipe Ferreira Vander Velden}

\section{(2) OpenEdition \\ 1 Journals}

Edição electrónica

URL: https://journals.openedition.org/aa/1009

DOI: $10.4000 / a a .1009$

ISSN: $2357-738 X$

Editora

Programa de Pós-Graduação em Antropologia Social (UnB)

\section{Edição impressa}

Data de publição: 1 dezembro 2011

Paginação: 55-76

ISSN: 0102-4302

\section{Refêrencia eletrónica}

Felipe Ferreira Vander Velden, «Inveja do gado: o fazendeiro como figura de poder e desejo entre os Karitiana», Anuário Antropológico [Online], v.36 n.1 | 2011, posto online no dia 10 novembro 2015, consultado o 07 dezembro 2022. URL: http://journals.openedition.org/aa/1009 ; DOI: https://doi.org/ 10.4000/aa.1009

\section{(c) (1) (9)}

Creative Commons - Atribuição-NãoComercial-SemDerivações 4.0 Internacional - CC BY-NC-ND 4.0 https://creativecommons.org/licenses/by-nc-nd/4.0/ 


\section{Inveja do gado: o fazendeiro como figura de poder e desejo entre os Karitiana*}

Felipe Ferreira Vander Velden

Universidade Federal de São Carlos

No final de uma manhã de setembro de 2006, cheguei à Casa do Índio de Porto Velho, prédio anexo ao escritório da regional da Funai na capital rondoniense que hospeda temporariamente os índios de passagem pela cidade, além de várias famílias que ali vivem permanentemente, pois seus membros exercem atividades diversas na zona urbana. Na ocasião acontecia um grande churrasco de carne bovina, e praticamente todos os Karitiana - povo de língua tupi-arikém que vive em três aldeias não muito distantes da cidade - estavam ali reunidos, pois naquele momento protestavam contra certas atitudes do órgão indigenista federal. Soube, então, que a carne - um boi inteiro, já abatido e carneado - fora doada por um político local: um candidato a uma cadeira na Assembleia Legislativa de Rondônia. Vivíamos a intensa campanha eleitoral que definiria os perfis dos governos federal e estaduais em outubro daquele ano. Mais para o final da festa, o próprio candidato apareceu na Casa do Índio, conversou com alguns karitiana - muitos deles eleitores - e deixou o local após alguns minutos.

Estranhei aquilo tudo: pensava, até então, que os Karitiana não consumiam carne bovina. Conversando dias depois com os índios, vim a saber que aquele não era um evento extraordinário: era relativamente comum que políticos em busca de votos e proprietários rurais vizinhos à Terra Indígena Karitiana doassem aos índios carne bovina em portentosas quantidades para a realização de churrascos, tanto na cidade quanto nas aldeias. Além disso, parte do pouco dinheiro adquirido pelas famílias era empregado na compra de cortes baratos de carne, consumidos na cidade ou, por vezes, enviados aos parentes que permaneciam nas aldeias. De fato, os Karitiana apreciavam, e muito, a carne vermelha dos bois. Nada surpreendente, afinal: sabemos há tempos que as sociedades amazônicas só consideram uma refeição completa quando ela contém carne, e várias culturas possuem mesmo um termo que descreve a "fome de carne" como uma sensação distinta da fome em geral (ver Camargo, 1999:132, para o Kaxinawá, como exemplo).

Além disso, o gosto pela carne bovina entre os Karitiana determinava, a crer nas falas dos índios, o desejo e a intenção - manifestada com frequência, especialmente por lideranças - de introduzir a criação de bois em Kyõwã, a maior e mais antiga 
aldeia karitiana, situada quase no centro da Terra Indígena Karitiana. Nunca houve bois em Kyõwã, mas esses grandes herbívoros exóticos - introduzidos apenas após o contato com os brancos - parecem sempre ter estado presentes, seja nos discursos em torno da vontade de tê-los como forma de solucionar alguns problemas contemporâneos, seja nos projetos desenhados desde os anos de 1980 para efetivamente colocá-los lá. Ambos, discursos e projetos, estavam (e estão) na boca de índios e de não índios que se relacionam com os Karitiana e com eles elaboram políticas. Recapitulemos.

As tentativas de se iniciar uma verdadeira atividade pecuária entre os Karitiana não são de hoje. Em 1983, o grupo já manifestava interesse pela criação de gado (Mindlin \& Leonel Jr., 1983:55, 60). No ano de 1986, um técnico agrícola e um engenheiro agrônomo da Funai apresentaram um "Projeto de Pecuária do P.I. Karitiana”, que visava atender à população local na sua parte alimentar por meio da produção de leite, a partir da aquisição de cinco novilhas da raça Gir/Holanda. O documento ${ }^{1}$ informava ainda a expectativa do grupo: "a comunidade do PI Karitiana está certa de que o início desta criação [de vacas] só trará benefícios a todos, pois é um tipo de atividade esperado há muito tempo".

Em 1995 técnicos do PLANAFLORO apresentaram novo projeto, que contemplava bovinos, suínos e muares. ${ }^{2}$ Ambos os projetos jamais foram implantados, mas as expectativas permaneceram: muitos dos índios - homens, diga-se de passagem - entusiasmaram-se com uma nova possibilidade de introduzir um pequeno rebanho na aldeia. Em 2003, Renata Maranhão detectou este desejo, materializado nas primeiras iniciativas de instalação da criação bovina na área:

A comunidade almeja uma futura criação de gado para que possa complementar sua alimentação. Para isso, já foi realizado um plantio de 2ha de Braquiária, ${ }^{3}$ para se dar início ao processo. Entretanto, a braquiária vem se alastrando para outras roças [sic], o que pode proporcionar futuros problemas por ser de larga adaptação e uma espécie pioneira, ou seja, de rápida propagação devido à alta produção de sementes viáveis (Maranhão, 2003:50).

A autora aponta, corretamente, para o impacto ambiental provocado pela difusão descontrolada da gramínea adventícia, mas em 2006 e em 2009 não ouvi dos Karitiana referência à formação artificial de zonas de pastagens. Não obstante, a vontade de criar gado permanecia forte. Desde 2004 a Emater- $\mathrm{RO}^{4}$ acena com a possibilidade - materializada em um projeto elaborado em parceria com a Funai (na figura do chefe do posto) e a Associação Indígena Karitiana (Akot Pytim Adnipa, ou APK) - da cessão de dez vacas leiteiras e um macho reprodutor para o grupo, 
além da construção de um cercado. Em janeiro de 2005 os Karitiana, por meio de sua Associação, elaboraram proposta para o uso dos recursos advindos da comercialização de madeiras desvitalizadas, que incluía desenvolver a criação de gado (com plantio de pasto). A solicitação do grupo foi encampada pelo "Projeto de Apoio às Atividades Agropecuárias em Terras Indígenas - Comunidade Indígena da Etnia Karitiana", ${ }^{5}$ um ambicioso projeto que incluía a aquisição de 96 matrizes e quatro reprodutores bovinos mestiços euro-zebu (Girolanda). Propôs-se ainda a construção de um curral de madeira com $768 \mathrm{~m}^{2}$ e três cochos para sal; recursos também seriam necessários para a aquisição de vacinas e medicamentos veterinários, de sal mineral, de arame e de outros implementos. O orçamento total, só dos animais e dos insumos necessários para a implantação da criação, chegou a quase R\$ 190 mil.

Até agosto de 2009, contudo, a doação vinha sendo protelada, muito em função da carência de estrutura para receber os animais: leia-se falta de pastagens e de conhecimento técnico adequados por parte dos índios (o Projeto propõe "cursos de capacitação”, mas sua natureza não é especificada). De acordo com o então chefe do P.I. Karitiana, em 2009 a criação dos bois já estaria instalada, se um incêndio não tivesse acidentalmente destruído as estacas de madeira que Antônio José Karitiana cortara e preparara, pois o arame já fora cedido pela Emater.

O entusiasmo por projetos e por bois (penso que são duas coisas distintas), expresso nesses documentos pelos proponentes não índios das iniciativas, é compartilhado pelos Karitiana de hoje, que continuam demonstrando interesse e excitação com essas propostas. Dizem os Karitiana que a chegada dos bois deverá afastar o espectro da carestia em uma área em que a caça se torna mais e mais escassa, devendo ser procurada cada vez mais longe da aldeia. A carne bovina produzida na aldeia deve, portanto, melhorar o consumo alimentar das famílias, e ao mesmo tempo liberar vários homens da árdua tarefa de caçar: muitos homens mais velhos hoje admitem ainda caçar apenas porque suas esposas e filhos reclamam carne, obrigação que abandonariam de bom grado, dizem, se dispusessem de uma provisão constante de carne de criação. Aqui, começamos a destacar algumas questões.

Prossigamos por partes. Não sou biólogo nem ecólogo - e por isso não posso afirmá-lo categoricamente, e tampouco existem estudos a respeito que me permitam fazê-lo - mas minha impressão geral em um ano de pesquisa de campo é que a caça não é exatamente um recurso escasso na Terra Indígena Karitiana. ${ }^{6}$ Não só avistar animais na mata é comum como diariamente os caçadores retornam com presas abatidas, e não é frequente que um homem que saia à procura de carne retorne de mãos abanando; algumas caçadas coletivas que acompanhei produziram uma quantidade significativa de carne. É certo que alguns caçadores são melhores 
do que outros, e os mais velhos se ressentem de não terem mais a disposição da juventude. Mas é fato também que muito poucas vezes os Karitiana não têm carne de caça para comer.

No entanto, a afirmação da escassez de carne de caça é virtualmente unânime, e me parece expressar várias coisas. Por exemplo, pode derivar da percepção de que a floresta no entorno da aldeia Kyõwã vem mudando nas últimas décadas em função da sedentarização do grupo e de seu substancial crescimento demográfico. Pode também falar de um desejo sempre presente de ter carne à mesa, na maior quantidade e variedade possíveis, fazendo com que o menor indício de desabastecimento seja lido com preocupação; ademais, a escassez de caça pode ser ressaltada pelos índios diante da abundância demonstrada pelos brancos, especialmente pelos fazendeiros, para quem a carne, aos olhos dos Karitiana, nunca falta. Estas três possíveis razões para o discurso da escassez de caça certamente são influenciadas por algo como uma "glorificação" do passado, feita pelos Karitiana, sobretudo depois que uma nova aldeia foi erguida às margens do rio Candeias, considerada zona de abundância de caça e pesca, que espelha o território indígena antes do contato devastador com os brancos, donos de poder e riquezas que os índios desejam intensamente (Vander Velden, 2010b). Entretanto, parece-me também plausível sugerir que esta formulação da carência atual constitua uma estratégia formulada pelo grupo e que depende da afirmação categórica de que a caça está difícil: uma escassez discursiva e intencionalmente produzida.

Avancemos um pouco mais nos caminhos dos discursos indígenas. Na minha tese de doutorado (Vander Velden, 2010) colecionei exemplos que apontam que a maior parte dos projetos de criação sistemática de espécies animais ${ }^{7}$ implantados em aldeias indígenas na Amazônia falhou desastrosamente. Conforme observou Peter Schröder (2003:95-96):

No Brasil, as experiências com a pecuária bovina em terras indígenas na Amazônia Legal geralmente foram desestimuladoras, pois elas se fundamentaram, na maioria dos casos, em pressupostos errôneos sobre as culturas indígenas e necessitaram de grandes mudanças culturais da organização econômica indígena.

A mesma percepção tem um funcionário da Funai de Porto Velho com quem conversei sobre o tema em 2009:

Hoje a Funai tem projeto só de criação de pequenos animais nos Karitiana. Tem projeto de criação de galinhas caipiras, criadas soltas. Um tanto já foi doado, mas falta levar outras, entre 100 e 150 galinhas, dando umas três ou cinco aves para 
cada família criar. Todo tipo de criação comunitária não dá certo, se a comunidade tem outras atividades, por exemplo, agricultura. O boi não fica preso, ele ataca os roçados dos outros. Cabra ataca ainda mais, é pior. Não dá certo, por isso a Funai não investe mais nisso.

Os fracassos sucessivos nos projetos de criação animal repetem-se no caso dos Karitiana, em que a introdução de um pequeno plantel caprino nos anos 80 e de galinhas de granja criadas em confinamento anos depois foram um fiasco, ambas as atividades abandonadas com pouco tempo transcorrido de sua instalação (Vander Velden, 2010:140-143).

Várias foram as razões alegadas para esses fracassos na introdução da criação animal entre populações indígenas e, para os Karitiana, a criação de cabras e galinhas não vingou primordialmente por falta de insumos, conhecimento e capacitação técnica adequada, descompromisso do grupo com iniciativas de caráter comunitário (já que a produção é organizada por unidades familiares) e, no caso das galinhas, "brancas, de granja" (portanto, diferentes daquelas criadas nos terreiros das casas), o estranhamento provocado por aquelas aves confinadas à espera de alimento - o que significava que uma parte da produção de milho teria de ser desviada para alimentá-las.

Mas há também, ao que parece, razões de outra ordem para o fracasso dessas atividades, em princípio estranhas aos modos indígenas de produção e de relação com seres não humanos. No meu texto (Vander Velden, 2010), demonstrei que os animais de criação ${ }^{8}$ - sejam os xerimbabos nativos, como macacos, quatis e psitacídeos, sejam aqueles introduzidos pelos brancos com o contato (cavalos, burros, cães, gatos, galinhas, porcos) - são familiarizados por conta da convivência intensa e cotidiana com os grupos familiares e, por esta razão, não podem ser comidos - e só o são, de fato, muito raramente. Diz-se do animal de criação que é "como um filho", e um filho, obviamente, não se come. Esses animais podem ser vendidos, trocados, presenteados ou roubados, mas jamais se devora sua própria criação. Desta forma, os bois doados pelos fazendeiros são degustados com prazer, mas não resta evidente - e só a experiência dirá - se virão a comer os bois caso estes venham a ser criados na aldeia.

O mecanismo de familiarização dos animais criados junto aos homens descrito para muitas cosmologias amazônicas e objeto de reflexão de alguns autores (Erikson, 1987; Cormier, 2003, entre outros) - representa, pois, do meu ponto de vista, um sério impedimento à introdução da pecuária nas aldeias karitiana: se criarem adequadamente, se conviverem diuturnamente com esses seres e, sobretudo, se alimentarem diretamente os animais - como se faz com as crianças - é bem 
plausível supor que os índios não irão abater e consumir seus rebanhos. Isto, aliado ao fato - também óbvio na Amazônia indígena - que caça e carne não são termos exatamente equivalentes (pois caçar não significa apenas prover-se de carne, mas a prática está ligada a vários outros domínios sociais e cosmológicos, como as relações de gênero e as classificações e as taxonomias do mundo natural), leva-nos a formular a seguinte questão: se comer animais de criação é algo improvável para os Karitiana, o que mais pode estar sendo dito quando os índios afirmam que querem gado para resolver o problema da falta de caça e da fome de carne? O que nos leva a uma segunda indagação: para o que mais, então, os Karitiana querem rebanhos bovinos?

$$
* * *
$$

Destaquemos a pujança do agronegócio brasileiro nos dias correntes, com particular atenção para a pecuária bovina. Com efeito, o Brasil já possui o maior rebanho de bois do planeta, e é o maior exportador de carne bovina entre todos os países (Barbosa \& Molina, 2007). Há uma vultosa aposta na pecuária como um dos carros-chefe do desenvolvimento da nação, e isso muito puxado pela expansão das frentes pastoris Amazônia adentro, ocupando áreas supostamente desocupadas ao custo da devastação da floresta para a formação de imensas áreas de pasto (Smeraldi \& May, 2008, 2009). Rondônia, evidentemente, não está imune a este cenário emulando a pujança alcançada pelo agronegócio no vizinho Mato Grosso, e configurando a expansão destas frentes colonizadoras em direção ao norte e ao oeste; o estado já é o quinto exportador de carne entre os estados da federação, ${ }^{9}$ e vê a pecuária do boi tornar-se cada vez mais procurada e incentivada. Duas enormes feiras agropecuárias são realizadas anualmente em Porto Velho e em Ji-Paraná e, em 2009, durante minha pesquisa de campo em Rondônia, um adesivo distribuído à população pregava: "Rondônia, estado natural da pecuária".

Além disso, vigora na região - como em outras partes do território nacional - o discurso da pecuária como ação civilizadora, que abriu definitivamente aquela área à ocupação humana racional e ordenada, na qual o domínio do homem sobre os animais (bois e cavalos, sobretudo) espelham o controle daqueles sobre o território e sobre a natureza (Rivière, 1972; Pimentel, 1997) - herança da tradição agropecuária ibérica, masculina (machista, pode-se mesmo dizer), vigorosa, rude e conquistadora (Baretta \& Markoff, 1978).

Estudos em vários pontos da Região Norte do Brasil (Bastos da Veiga et alli, 2004; Toni et alli, 2007) vêm indicando que a aquisição de plantéis bovinos é excelente alternativa econômica mesmo para pequenos proprietários, colonos, seringueiros e outros extrativistas: atividade mais rentável que as tradicionalmente 
exercidas por estas populações, a pecuária - de corte ou de leite - permite que eles se vinculem a cadeias produtivas cada vez mais organizadas na região Amazônica e, assim, garantam uma base econômica mais sólida e menos sujeita a flutuações do mercado e das condições infraestruturais. Ademais, suas reses (e as pastagens de que precisam) naturalmente ocupam as terras, marcando sua apropriação de forma mais segura (em contraste com áreas de mata): lembremos que, no interior do Brasil, "terra com gado é terra com dono" (Rivière, 1972; Fearnside, 1989). Enfim, a pecuária bovina gera segurança econômica, gera riqueza.

E gera poder, obviamente, e aqui encontramos os fazendeiros. Figuras de grande prestígio e importantes posições na sociedade regional e nas estruturas políticas deste estado nortista, colonizado principalmente por paranaenses e mato-grossenses com forte tradição agropecuarista (Perdigão \& Bassegio, 1992), os fazendeiros rondonienses têm como epítome a própria figura do governador Ivo Cassol ${ }^{10}$ (no PP desde 2010), durante oito anos no poder, e que para onde ia portava sempre sobre a cabeça um chapéu de palha australiano, bem ao estilo da elite pecuarista local. ${ }^{11}$ Fazendas imensas, casas luxuosas, caminhonetes importadas, helicópteros, jóias de ouro e uma infindável disposição para se imiscuírem na vida pública e dela extraírem vantagens, os fazendeiros-pecuaristas dominam a cena econômica e política de Rondônia. Fortes nas zonas urbanas, seu poder realiza-se plenamente, como haveria de ser, nas áreas rurais do estado, muitas vezes nas proximidades das terras indígenas.

Fazendeiro é o modo como os Karitiana se referem a seus poderosos vizinhos do norte. Com efeito, a Terra Indígena Karitiana, demarcada e homologada, é praticamente um quadrilátero de aproximadamente 89 mil hectares, integralmente localizado no município de Porto Velho. Os limites sul e leste da área estão contornados pela Floresta Nacional (Flona) do Bom Futuro, enquanto a fronteira oeste encontra-se ainda razoavelmente protegida pela floresta. O norte da Terra Indígena, contudo, é ocupado por uma sucessão de grandes propriedades fundiárias que margeiam a BR-364 no sentido Rio Branco-Porto Velho; da mesma forma, a estrada vicinal que dá acesso à Kyõwã corta várias fazendas até os limites oficiais do território karitiana, e o que vemos são a mata derrubada, pastagens e mais pastagens, bois e mais bois. Esta vizinhança nem sempre é pacífica: por vezes, funcionários de algumas dessas fazendas - sabe-se lá se intencional ou acidentalmente - invadem a área indígena com suas atividades (plantações, benfeitorias). Outras vezes, como vi ocorrer em 2006, o fazendeiro efetua o barramento de rios e igarapés para a formação de lagos ou açudes no seu terreno, o que prejudica o regime das águas e a pesca na terra karitiana, pois os cursos d'água mais explorados pelos índios correm para o norte, para desaguar no rio Madeira, não sem antes banharem as proprie- 
dades rurais que se espalham entre a rodovia e a área indígena. Tais acontecimentos invariavelmente geram confrontos.

Mas as relações entretecidas entre os Karitiana e seus vizinhos fazendeiros nem sempre são conflituosas. Vimos, no início deste texto, como políticos em busca de votos costumam ceder carne bovina de seus rebanhos aos índios. Os fazendeiros da região fazem o mesmo com alguma frequência, e os Karitiana se comprazem em recordar grandes churrascos em Kyõwã, de reses inteiras, patrocinados pelos poderosos moradores das terras contíguas às suas. O projeto de introdução da pecuária bovina idealizado pela Emater em 2004 previa, como visto acima, a doação de 11 reses aos índios, e algumas destas seriam presenteadas por um fazendeiro. Outras benesses são também ofertadas aos Karitiana por estes homens, que não animais ou sua carne; penso, contudo, que este dado é significativo.

Recentemente, em 2009, um grupo oriundo de Kyõwã fundou uma nova aldeia na região do Igarapé Preto, norte da Terra Indígena, zona de ocupação tradicional deste povo; sem entrar no detalhamento das forças políticas - indígenas e não indígenas - envolvidas nesse processo (ver, sobre isso, Vander Velden, 2010b), destaco que a aldeia foi erguida fora dos limites da área demarcada, nas terras de um fazendeiro que estava, até onde sei, apoiando a iniciativa. As fotos tiradas pelos próprios Karitiana que ocuparam a nova aldeia mostram uma infinidade de bois circulando nas imediações.

Destaquemos, pois, que os Karitiana não apenas convivem cotidianamente com fazendeiros, e têm razões várias para admirá-los e entretecer com eles relações de amizade e confraternização. ${ }^{12}$ Têm, igualmente, razões para temê-los, uma vez que muitos dos episódios de desrespeito aos limites do território indígena protagonizados pelos fazendeiros não encontram solução em função do poder político dos personagens envolvidos (como foi o caso do barramento do igarapé em 2006, que estava acabando com as jatuaranas ${ }^{13}$ à montante), e o uso de intimidação e de violência não é incomum: a outra aldeia karitiana, Byyjyty ot'soop'waky, também construída fora dos limites demarcados (ver Vander Velden, 2010b), é constantemente ameaçada por pistoleiros e capangas contratados pelos fazendeiros que ocupam o leste da Terra Indígena e temem perder suas propriedades se a ampliação da área karitiana for efetivada (processo que se arrasta pelo menos desde 2002).

Os fazendeiros são admirados e temidos por seu poder, sua riqueza e ainda pelo seu conhecimento: dizem alguns karitiana que não adianta trazer bois para a aldeia Kyõwã porque os índios não sabem criar animais, só "fazendeiro é que sabe criar animal, dão vacina, dão ração”. É o domínio de uma técnica, portanto, que parece fundamentar o sucesso dos pecuaristas com os quais os índios têm contatos. E os Karitiana querem, eles mesmos, manejar este saber, daí sua preocupação com a 
instrução, o treinamento prévio adequado para que se realize, também na Terra indígena Karitiana, a "utopia do Banco Mundial, relativa a um paraíso bovino na floresta tropical” (Taussig, 1993:376). ${ }^{14}$

Os Karitiana desejam, há tempos, a introdução da pecuária bovina em suas terras, mas espero ter demonstrado que as razões evocadas por eles são contraditórias à luz de suas relações com os animais, suas práticas produtivas e suas concepções simbólicas, além de não encontrarem exata correspondência na sua realidade vivida. Entretanto, se querem criar animais, mas só "fazendeiro é que sabe" sobre a criação animal, é preciso, então, se tornar fazendeiro. Penso que o grupo quer a implantação, em Kyõwã, de um rebanho e da estrutura necessária para manejá-lo não exatamente, ou não somente, para solucionar os problemas de fome, carência nutricional ou rarefação da fauna silvestre - conforme acreditam os proponentes e os analistas não índios dos projetos - mas para se converterem em fazendeiros e adquirirem todos os bens, a riqueza, o poder, o sucesso e o prestígio de que dispõem alguns de seus vizinhos. Esta interpretação, creio, encontra sustentação na cosmologia karitiana.

"Fazendeiro é que sabe", dizem os Karitiana, como já aludimos, o que os aproxima de Boty $\sim j^{15}$ (que eles traduzem como Deus), principal divindade karitiana e o grande criador de todos os seres que povoam o universo. Criador, aqui, na dupla e instigante acepção que o termo tem na língua portuguesa: primeiro, aquele que cria, produz, inventa, monta, desenvolve e, segundo, aquele que cria, provê, protege, controla, cuida.

É interessante constatar que a forma curral não é desconhecida dos Karitiana: Boty j criou todos os animais a partir da junção de pedaços de elementos diversos (tocos de madeira, cupinzeiros, cascas de frutas, entre outros) e colocou-os todos em um grande curral que construíra para isso, como me contou Epitácio: "Deus queria comer caça, e daí formou cada animal de caça, pássaros, bicho do mato, todos no curral, como branco está fazendo com boi” (meu grifo).

Não que haja qualquer correspondência entre a mitologia e o saber técnico, mas é digno de atenção que os Karitiana traduzam como curral, ou chiqueiro (poon), a estrutura criada por Boty $\sim j$ no início dos tempos, assumindo sua homologia com a atividade de criação de animais em confinamento. Reproduzo fragmento do mito que conta a origem da caça, narrado novamente por Epitácio:

Antigamente não tem [tinha] carne, caça, só esse sapo mamo, que os Karitiana comiam. Deus só comia ovos de sapo. Mas Deus queria comer caça, e daí formou cada animal de caça, mutum, porcão, anta, todos em um curral, como branco está fa- 
zendo com boi. Ora [irmão de Boty j] vai buscar tuna [pom'emo, ave do grupo dos nambus], que mulher de Deus, Toboto, pediu para comer com pamonha que ela estava fazendo. Ora respondeu com voz fina, foi no curral e jogou milho, depois abriu a porta do curral, e todos os bichos saíram correndo, passando por cima, amassando ele. Por isso as caças estão tudo no mato. Deus estava longe, fazendo outra coisa, mas ele descobriu quando juriti [kyytsoopo] caiu [apareceu] bem na frente dele (meus grifos).

Depois disso, Boty $\sim j$ estabelece a dieta dos seres, ao oferecer a cada espécie seu alimento preferencial, típico: ele alimenta os animais, assim os definindo como suas criações no segundo sentido da palavra. Ou seja, Boty $\sim j$ é como se fosse o primeiro criador de gado, e é com seus animais confinados, libertados acidentalmente por um ato desastrado de seu irmão Ora, que a floresta é povoada pela caça que sustenta os Karitiana até hoje, diversificando uma alimentação até então baseada na carne do sapo mamo, "a primeira caça/carne do índio". É interessante que Boty $j$ continue sendo, ainda hoje, um criador de animais, como destaca este outro fragmento que descreve as cenas que Deus mostrou em sua comunicação constante com o pastor Luís Francisco Karitiana:

Lá no céu tem todo tipo de criação, Deus cria todo tipo de criação. Também cria galinha, porco, boi, cachorro, só que são maiores e mais bravos do que os daqui [...]. Deus mostrou a plantação d'Ele, e diz que vai dar para mim, e mostrou também sua criação [animais].

No que é completado por Antônio Paulo: "Deus tem muita criação, ele cria, anta, mutum, tuna”. Este mesmo informante, aliás, destaca que os próprios Karitiana veem a si mesmos como "criação de Deus", aparentemente nos dois sentidos: que foram criados ou feitos por Deus, e que são cuidados por ele, tal como os Karitiana cuidam de ou criam seus animais de criação.

É preciso salientar que o modelo do curral de animais não é exclusivo da cosmologia karitiana, sendo difundido em várias outras sociedades descritas pela etnografia (para diversos exemplos de currais, gaiolas ou caixas de animais confinados entre povos indígenas amazônicos, ver Vander Velden, 2010:148-149). Não obstante, as evidências discutidas por Fausto (2008) apontam que esses currais (também chamados, por alguns povos, de fazendas ou cercados) em geral são propriedades (aqui, talvez, nos dois sentidos: do que pertence ao e do que é próprio de) das figuras usualmente conhecidas como donos, pais ou mestres da caça, dos animais ou de cada espécie em particular: esses seres mantêm os animais de caça confinados 
- combinando, na sua relação com eles, controle/domínio e proteção/cuidado - e vão liberando-os na floresta na medida de suas conveniências. Este, contudo, é um mecanismo permanentemente em ação, que depende da qualidade das relações cotidianas entre os humanos e os mestres e "seus" animais: as negociações que os humanos devem entabular para obter a dispersão das presas de caça são atividades permanentes. O esquema karitiana, pode-se já ver, é diferente: Boty j não é um mestre da caça, mesmo porque a libertação/dispersão dos animais mato afora ocorreu apenas uma vez, lá no início dos tempos míticos; ademais, nem mesmo foi Boty $\sim j$ - que é o criador (nos dois sentidos: de produtor e de pecuarista) original - o responsável por abrir as porteiras do curral mítico. ${ }^{16}$

Aos seres descritos como donos ou chefes de caça, os Karitiana dirigem o que chamam de orações destinadas a pedir os animais a serem caçados, e devem cuidar de não matar em demasia ou sem razão utilitária, nem em desperdiçar a carne, compartilhando-a, consumindo-a integralmente e depositando os despojos de modo adequado. Caso não sigam estas prescrições, o "chefe de caça fica bravo" (Marcelo), e o caçador torna-se imediatamente panema. A festa da caça (him myy j) é um ritual destinado a atrair animais para perto da aldeia para serem abatidos, e meus dados apenas sugerem que se trata de evento em que se opera uma negociação com os chefes de caça, embora eu não tenha elementos para sustentar definitivamente esta suposição. ${ }^{17}$ Cizino verbaliza o vínculo entre a caça e seus donos (ou chefes), sugerindo como metáfora a relação entre os brancos e os bois:

Chefe de caça também tem. Chefe de anta, chefe, não, dono, dono da caça. Dono. Dono tem. Como o senhor: você cria gado, pra você. Quem é dono? É Felipe. O mesmo ele tem [a]caça. [Se] Dono não deixar, a gente não mata anta; [se] dono não deixar, a gente não mata porco, entendeu? Se a gente está panema, muito, panema, a gente panema, muito, a gente fala [com] chefe dele: - cunhado, me dá onça pra mim, me dá anta pra mim, cunhado.

Mas é Boty j, em última análise, quem "sente" (sofre) pelos animais abatidos, e as sanções remetem ao respeito para com o Deus, que enviará doença e infortúnio ao caçador (e à sua família) que extrapolar os limites apropriados. Ademais, se Boty $\sim j$ criou os seres da floresta, ele, não obstante, criou-os para permanecerem fechados em seu curral; deste modo, é o ato impensado de Ora que, ao abrir a porta do cercado, efetivamente dá origem aos animais de caça, às presas, que a partir daquele momento deverão ser caçadas (e, temendo os homens, não serão mais alimentadas). Boty $\sim j$, portanto, parece ser o grande controlador dos seres (inclusive dos donos), o grande dono, além de ser o grande criador. É Cizino de novo quem 
arremata: "Dono de caça leva só cuidando, cuidando como Deus [Boty $\sim j]$, mesmo, porque Deus fez. O Deus. Cuidando de tudo, Deus manda ele [dono de caça] cuidar [do] povo da caça, arara, macaco, macaco-preto, tudo, tudo, tudo”.

Destaco que os Karitiana só raramente descrevem os animais da floresta como animais de criação dos donos/chefes de caça, e não mencionam a existência de currais ou chiqueiros sob o controle destas criaturas. O foco parece estar na libertação dos animais de caça nos tempos míticos, e os chefes/donos de caça parecem agir mais como prepostos de Boty $\sim$, cuja idealização do confinamento dos animais permanece como modelo dominante. Ou permaneceu, pelo menos até a chegada dos brancos.

Boty $\sim_{j}$ - e os donos de caça em menor grau - encarna a posição destes seres magnificados (como os chama Fausto 2008), que definem sua relação com os animais em termos de confinamento e controle. Note-se, então, que de fato o balanço entre proteção/cuidado e predação/domínio - bastante bem formulada na ideia do controle - parece ser em tudo análoga à relação que o criador de gado/pecuarista estabelece com seus animais ${ }^{18}$ estes, sim, sabemos muito bem, expressam a ambiguidade entre o cuidado e o desleixo (cujos limites são a mutilação e o abate) para com os animais domésticos. Fausto (2008:334) argumenta que o cercado de animais dos mestres da caça expressa a assimetria da relação entre uns e outros por meio da linguagem do englobamento, do continente-conteúdo: com efeito, o mestre-singularidade contém em si a pluralidade dos seres que enclausura. Estas são figuras da abundância e do poder.

Mas, querendo insistentemente criar gado, estarão os Karitiana almejando ser Deus? Não creio, e esta é uma hipótese absurda, ${ }^{19}$ porque falta aos Karitiana a capacidade de criar seres no sentido de construir, de fazer (make), atributo divino. Eles parecem querer, sim, ser fazendeiros, ou ser como fazendeiros. Eles parecem querer o poder, a abundância e a riqueza desses brancos que dominam as técnicas de criar animais, e surgiram para os Karitiana, desde sempre, cercados por suas criações, que só fazem espalhar pelos pastos que dominam Rondônia e multiplicam fortunas do negócio agropecuário. O fazendeiro é uma espécie de réplica enfraquecida de Boty $\sim$ j na Terra, tendo realizado, aqui e agora, o feito da divindade no início dos tempos: criam animais em seus currais, animais que, num certo sentido, eles criaram (produziram), uma vez que os Karitiana reconhecem que os bois - como as demais espécies introduzidas pós-contato - foram trazidos "pela mão do branco", e não feitos por Boty $\sim j$ como os seres da floresta. ${ }^{20} \mathrm{Ou}$ seja, desde sempre, os rebanhos aparecem na companhia dos brancos, como formas de sua riqueza, de seu poder transformador, de seu saber. É digno de nota que a memória karitiana do surgimento dos bois recorde as fazendas, áreas cuja natureza já havia sido modificada pela ação dos invasores: 
Tempo antigamente os Karitiana andavam muito longe, lá, outro país, muito longe, não sei onde, [onde tem] americano [sugerindo grande distância], lá, e viram num campo e vieram para contar que viram anta diferente [bois, opok irip', “anta dos brancos" ${ }^{21}$, veado grande [de ty, "veado grande”, isto é, cavalos ou burros], casa diferente. Voltaram para contar para o povo. Diz que depois Deus $[$ Boty $\sim j]$ ensinou os brancos a criar, e aí os Karitiana viram nas mãos dos brancos esses animais (Epitácio Karitiana).

Os Karitiana sempre manifestaram interesse por essas criaturas exóticas trazidas com o contato, como mostrei na minha tese (Vander Velden, 2010: 60-86). Uma rápida nota em relatório sobre a comunidade karitiana (Mindlin \& Leonel Jr., 1983:54-55) fornece um vislumbre desse interesse: "[Os Karitiana] perguntam aos colonos e fazendeiros das vizinhanças como obter dinheiro e discutem as atividades mais rentáveis. Alguns começaram a criar porcos, outros, galinhas [...]”.

O gado, como disse, é sinal de riqueza e de poder, e a pecuária é em geral tida como atividade de status mais elevado do que a agricultura, mesmo na Amazônia (Fearnside, 1989:25; Piketty et alli, 2004:184-185; Bastos da Veiga et alli, 2004:2629; Toni et alli, 2007:64, 104). É também signo do poder e do controle, além de marca inequívoca do domínio sobre a terra: lembremos que "terra com gado é terra com dono" (Rivière, 1972; Fearnside, 1989). A pecuária é ainda emblema da civilização, do controle produtivo sobre terras novas, bravas e incultas (Anderson, 2004). O gado é, enfim, o que sugere Philippe Descola (1996:167): “[...] objeto de uma transferência metonímica que o torna apto a exprimir as qualidades e as aspirações daqueles que o possuem, e suscetível, por conseguinte, de servir de suporte de posições sociais [...]".

É esta qualidade de poder expressar posições sociais, penso, que os Karitiana almejam a partir dos animais de criação introduzidos. ${ }^{22}$ Mas se não podem criar (make) os animais, eles tampouco sabem criá-los (grow), como dizem, e daí a necessidade de conhecimento e instrução técnica, pois o fazendeiro (como Boty $\sim_{j}$ ) é também figura de conhecimento. Esta alegada falta de saber técnico fundamenta a percepção karitiana do fracasso dos projetos de criação até hoje tentados: os animais soltos não respeitam roçados, ninguém se interessa pelos animais confinados, a comunidade não se manifesta, e o resultado é o desastre, a não reprodutibilidade, a doença e a morte, frequentemente cruel. Como bem percebeu Michael Taussig (1993:375-380), a inveja do gado (the envy of cattle) só faz disseminar a violência, a corrupção e o mal. 
Não quero sugerir com tudo isso que os Karitiana não possam, com o tempo e ao cabo, aprender as técnicas necessárias para se tornarem, efetivamente, criadores, fazendeiros: isto significaria defender certo atavismo nas populações amazônicas que as manteria presas a economias de caça, coleta e horticultura, jamais podendo diversificar suas atividades econômico-produtivas (cf. Gordillo, 2006). Também não vejo, em princípio, nenhum mal em que os Karitiana se tornem fazendeiros, criadores de bois: afinal, o desejo por ter fartura de carne é sincero, e representa certamente a intenção dos índios em alcançar a plenitude na oferta de alimentos. Penso, apenas, que a implantação de tal alternativa econômica ali deve levar em conta os múltiplos fracassos já experimentados por outras populações amazônicas com a pecuária bovina (ver Vander Velden, 2010), além dos múltiplos impactos de ordem ambiental (desmatamento, pisoteamento do solo, expansão descontrolada de gramíneas forrageiras, competição com espécies nativas) e sanitária (introdução de zoonoses, contaminação de solos, cursos d'água e lençol freático) que o gado causa nos territórios onde se instala, fatos já registrados em outras áreas indígenas (Fearnside, 1989; MacDonald, 1997; Leite 2007). Penso, além disso, na reprodução das relações de desigualdade, no momento em que o gado se converte em fonte de riqueza e se torna como um avatar de seu proprietário, acabando por reproduzir no interior das aldeias as hierarquias que opõem, globalmente, índios e brancos: interessa, no rebanho, não seus produtos, mas seu poder de materializar as distinções entre os homens, como sugerem Philippe Descola e Michael Taussig; dito de outra forma, interessa aos Karitiana o gado como símbolo de riqueza.

Acresça-se a isso, ademais, que a necessidade do controle reprodutivo dos animais de rebanho, aliada ao imperativo da manutenção e do aumento do plantel (isto é, do estoque), sugere modalidades de relação com os seres não humanos algo distintas daquelas encontradas tradicionalmente entre os povos nas terras baixas sulamericanas: com efeito, desta forma Descola (1994) explicou "por que os índios sul-americanos não domesticaram o pecari”.

Dezenas de povos indígenas na Amazônia brasileira desejam iniciar criação animal sistemática em seus territórios, e efetivamente têm encaminhado projetos desta natureza para as fontes financiadoras (Inglez de Souza, 2008). Estas últimas estão seguras de que tais iniciativas, se implantadas, serão a panaceia para a solução dos problemas de fome, carência de proteínas ou de calorias, escassez de caça ou segurança alimentar nas aldeias (Salgado, 2005, 2007; Guerra, 2008). Mas os fracassos já diagnosticados não apontam para outra direção? Para o fato, talvez, de que os índios não estejam almejando resolver problemas alimentares ou nutricionais, mas sim emular a figura de poder e prestígio que é o fazendeiro (pecuarista) nos rincões do Brasil? Conforme demonstrou admiravelmente Cesar Gordon (2006) entre os Xikrin- 
Mebêngokre, os bens capturados pelos povos indígenas no mundo dos brancos, via de regra, servem a propósitos internos a essas cosmologias que muitas vezes nada têm que ver com as proposições dos fornecedores não índios desses mesmos bens. Eles servem, frequentemente, não para produzir outros bens materiais (como colheitas agrícolas, alimentos, artesanato), mas para produzir relações. Os Karitiana querem o gado, penso, para produzirem relações, ou melhor dizendo, para reproduzirem, nas suas aldeias, as relações de poder e de sucesso que veem materializadas na figura dos fazendeiros. ${ }^{23}$

Deste modo, a inveja do gado (Taussig, 1993:375-380) talvez sugira não que os índios queiram aquilo que defende a chamada "indústria de projetos" para povos indígenas - segurança alimentar, oferta nutricional variada, combate à fome e à desnutrição, aumento dos estoques proteicos, e por aí vai - mas que desejem bois como símbolos do poder, da riqueza, da técnica, do conhecimento e do prestígio dos pecuaristas. Estamos aqui, provavelmente, diante de mais uma daquelas manifestações do fenômeno de "virar" ou "tornar-se branco", que tem sido analisado por vários autores (Vilaça, 2000; Kelly, 2005; Vander Velden, 2008), e que fala das estratégias dos povos indígenas na busca pela aquisição de qualidades e poderes dos não índios por meio de sua transformação ou metamorfose nestes seus opostos. Para os Karitiana, tudo bem virar branco, mas não qualquer branco: importante é se tornar fazendeiro.

Recebido em 28 de outubro de 2010

Aprovado em 9 de maio de 2011

Felipe Vander Velden é Professor do Departamento de Ciências Sociais da Universidade Federal de São Carlos (UFSCar). Endereço eletrônico: fvander@ufscar.br. 


\section{Notas}

* Este artigo foi apresentado nos seminários do Grupo de Estudos de Relações Interétnicas (GERI) da Universidade de Brasília (UnB) em 22 de setembro de 2010. Agradeço o estímulo, a colaboração e as sugestões de Marcela Coelho de Souza, Estevão Fernandes, Cristhian Teófilo da Silva, Stephen Baines, e dos pareceristas anônimos do Anuário. "Inveja do gado" (the envy of cattle) é a expressão por meio da qual Michael Taussig (1993) percebe a difusão e o acirramento das relações de desigualdade no Putumayo colombiano a partir da introdução dos rebanhos bovinos, e como este sentimento é "materializado", por assim dizer, nas acusações de feitiçaria que jogam luz sobre as assimetrias socioeconômicas na região.

1. "Projeto de Pecuária do PI Karitiana". Ministério do Interior - Funai $-8^{\mathrm{a}}$. DR Porto Velho/RO, 1986 (documento encontrado no arquivo do CIMI-RO, Porto Velho). O projeto incluía, ainda, a construção de curral, formação de 20ha (cercados) de pastagens com capim braquiarão e compra de vacinas e vermífugos; o custo total do projeto chegou a 130 mil cruzados.

2. O Planafloro (Plano Agropecuário e Florestal de Rondônia) é um programa federal (hoje vinculado ao Ministério da Integração Nacional, embora se encontre paralisado desde o término, em set./2002, do acordo de empréstimo internacional firmado com o Banco Mundial) cujo objetivo é promover o desenvolvimento sustentável do estado de Rondônia, a partir do equilíbrio entre diversas atividades produtivas (sobretudo agricultura, pecuária e extrativismo vegetal), conservação ambiental e proteção social

3. Capins do gênero Brachiaria, muito utilizados na formação de pastagens na Amazônia brasileira.

4. Associação de Assistência Técnica e Extensão Rural do Estado de Rondônia, a EmaterRO é uma associação civil, sem fins lucrativos, que desenvolve estudos e projetos agropecuários em parceria com as secretarias de Desenvolvimento Econômico e Ambiental do governo de Rondônia.

5. Elaborado pela Emater-RO, em parceria com o Ministério do Desenvolvimento Agrário (Secretaria de Agricultura Familiar e Secretaria Executiva Estadual do PRONAF - Programa Nacional de Agricultura Familiar), a Prefeitura Municipal de Porto Velho, a Cunpir e a Funai. Documento disponível nos arquivos da APK.

6. A Terra Indígena Karitiana, assim como a Flona do Bom Futuro - que contorna os limites sul e leste da T.I. e incide sobre quase 30\% da mesma - apresentam, ainda, boa cobertura vegetal, embora haja vários registros de invasões, desmatamento e ocupação ilegal (inclusive criação de gado) em ambas as áreas (Cardoso, Leandro \& Vale Jr., 2010).

7. Chamo de criação sistemática a manutenção permanente (e em permanente reprodução) de um coletivo de animais de acordo com as técnicas preconizadas pela zootecnia, pela veterinária e por um conjunto de práticas e saberes mais difusos denominados pecuária ou criação, e com a finalidade de utilização contínua desses animais e seus subprodutos (tração, transporte, investimento, ocupação territorial, alimentação, adubação, matérias-primas etc.) por meio do controle e da gestão de seus corpos vivos ou mortos. 
8. A expressão é karitiana, e se refere ao conjunto de animais que vivem na companhia dos humanos, agregando duas categorias que, para nós ocidentais urbanos, são distintas: os animais de estimação (mascotes, pets) e os animais de rebanho ou de criatório (destinados à exploração e ao consumo).

9. Dados de 2007. A informação está em www.pecuaria.com.br/info. php?ver $=2047$ \&language $=$ english $($ acessado em 15/02/2008). Entre 1970 e 1988 o rebanho bovino rondoniense aumentou 30 vezes (Hecht, 1993:691).

10. Recém-eleito para o Senado Federal por Rondônia (2010).

11. Não quero dizer que todas as fortunas de Rondônia têm origem na agropecuária. Estou me referindo, sobretudo, a um "gosto de classe", um "estilo de vida" (Bourdieu, 1983) que inclui referências ao universo rural, tanto materiais - fazendas para lazer e recreação, cavalos, investimentos em negócios agropecuários - quanto simbólicas - modo de vestir, preferências musicais, práticas alimentares etc. - mesmo que a riqueza não provenha totalmente dele.

12. Os fazendeiros também esperam dos índios algumas concessões - no mínimo, como vimos, votos em tempos eleitorais.

13. A jatuarana (pojpok) é um peixe ritualmente importante para os Karitiana, que têm uma festa da jatuarana que, como os demais ritos daquele povo, se destina a "trazer saúde e alegria para a comunidade" (diz-se que jatuarana é "peixe limpo, saudável, por isso bom para festa”). Por causa do barramento do igarapé e do sumiço dos peixes, esta festa não estava sendo realizada, e eu mesmo jamais pude observá-la.

14. Ou, para dizer de outra forma menos irônica, "um campo extenso de capim verde, cercado pela floresta”, conforme Stephen Baines (1991:242) ao refletir sobre o gado rapidamente introduzido entre os Waimiri-Atroari.

15. A ortografia das palavras na língua karitiana é baseada na proposta de Storto (1996), modificada devido às limitações do meu editor de texto: o "til” [ ] deveria estar grafado sobre a consoante que nasaliza; aqui, o sinal nasaliza a consoante que o sucede.

16. Ora, que efetivamente abriu o curral, libertando os animais, não é um chefe de caça, mas dos seres aquáticos: "ele é chefe de peixe".

17. É certo que este ritual (também chamado de festa do gopatoma, termo traduzido como "remédio de folha, remédio do mato") destina-se a "limpar" os corpos das pessoas, o que, no caso dos homens, possibilita que cacem com mais sucesso, posto que o fedor do corpo é uma das manifestações do estado de panema: um dos termos para este estado, naam, significa literalmente "podre" (cf. Landin, 1983:111, em que nãm = "podre"); o caçador panema é dito estar "podre" ou "ter mão podre", e o barulho das moscas que infestam seu corpo afugenta os animais (Vander Velden, 2004:135-147).

18. Entre os Chimane, na Bolívia, "o mestre é um proprietário que possui animais de estimação e pessoas a seu serviço. A figura é frequentemente comparada aos fazendeiros bolivianos com seu gado e seus vaqueiros" (Daillant, 2003 apud Fausto, 2008:356).

19. Como é absurda a ideia de ser como os chefes da caça, que não comem os animais, mas os protegem. Criar animais para matá-los e comê-los é uma questão complicada que se coloca para estes projetos de criação animal, como mostrei em Vander Velden (2010). 
20. Noto, contudo, que os Karitiana não reconhecem que os animais introduzidos com o contato tenham sido fabricados (made) pelos brancos; apenas que eles não foram feitos por Boty j, no início dos tempos, como ocorreu com os animais da floresta.

21. O termo é bastante apropriado, inclusive no contexto desta nossa discussão: um boi cedido por um fazendeiro ou político alimenta toda a aldeia (num churrasco), o mesmo que se diz quando uma anta é abatida.

22. Maurício Leite (2007:209) salienta que os Wari' esperam dos projetos de desenvolvimento menos o incremento da produção de alimentos do que opções alternativas de geração de renda e acesso a recursos financeiros.

23. Obviamente existem casos em que a criação animal introduzida em aldeias indígenas foi bem-sucedida. Em outros casos, houve fracasso absoluto, total. Em outros ainda, conforme argumentei em minha tese de doutorado (Vander Velden, 2010), houve um fracasso relativo, caso em que os animais se multiplicam e permanecem nas aldeias e nas terras indígenas, mas não são aproveitados ou explorados consoante os objetivos desenhados pelos projetos que determinaram sua introdução. Casos como estes deverão ser reavaliados, buscando-se elucidar as lógicas indígenas que presidem a manutenção de rebanhos e o acúmulo de animais para além de razões econômicas, materiais ou utilitárias. 


\section{Referências bibliográficas}

ANDERSON, Virginia DeJohn. 2004. Creatures of empire: how domestic animals transformed early America. Oxford: Oxford University Press.

BAINES, Stephen. 1991. 'É a FUNAI que sabe': a Frente de AtraçãoWaimiri-Atroari. Belém: MPEG/ $\mathrm{CNPq} / \mathrm{SCT} / \mathrm{PR}$.

BARBOSA, Fabiano \& MOLINA, Lívio. 2007. "Conjuntura da carne bovina no mundo e no Brasil”. Artigos Científicos do Portal Agronomia. Disponível em: www.agronomia.com.br/ conteudo/artigos/artigos_conjuntura_carne_bovina_mundo_brasil.htm. Acessado em agosto 2010 .

BARETTA, Silvio \& MARKOFF, John. 1978. "Civilization and barbarism: cattle frontiers in Latin America”. Comparative Studies in Society and History, 20(4):587-620.

BASTOS DA VEIGA, J.; TOURRAND, J.; PIKETTY, M.; POCCARD-CHAPUIS, R.; ALVES, A. \& THALES, M. 2004. Expansão e trajetórias da pecuária na Amazônia: Pará, Brasil. Brasília: Ed. da UnB.

BOURDIEU, Pierre. 1983. “Gostos de classe e estilos de vida”. In: Renato Ortiz (org.), Pierre Bourdieu - Sociologia. São Paulo: Ática.

CAMARGO, Eliane. 1999. "Alimentando o corpo: o que dizem os Caxinauá sobre a função nutriz do sexo”. Sexta-Feira, n. 4:130-137.

CARDOSO, Ivaneide; LEANDRO, Ederson \& VALE Jr., Israel. 2010. “Terra Indígena Karitiana e Floresta Nacional do Bom Futuro: destruição negociada em troca do desenvolvimento econômico”. In: J. Amaral \& E. Leandro (orgs.), Amazônia e cenários indígenas. São Carlos: Pedro \& João Editores. pp. 71-82.

CORMIER, Loretta. 2003. Kinship with monkeys: the Guajá foragers of eastern Amazonia. New York: Columbia University Press.

DESCOLA, Philippe. 1994. "Porquoi les indiens d'Amazonie n'ont-il pas domestique le pecari? Généalogie des objets et anthropologie de l'objetivation”. In: B. Latour \& P. Lemmonier (eds.), De la préhistoire aux missiles balistiques: l'intelligence sociale des techniques. Paris: La Découverte. pp. 329-344.

1996a. "Commentaire”. In: Serge Gruzinski \& Nathan Wachtel (eds.), Le noveau monde, mondes nouveaux. Actes du colloque organisé par le CERMACA-EHESS / CNRS. Paris: Éditions Recherche sur les Civilisations/Éditions de l'École des Hautes Études em Sciences Sociales. pp. 163-167.

ERIKSON, Philippe. 1987. "De l'apprivoisement à l'approvisionnement: chasse, alliance et familiarization en Amazonie Amérindienne”. Techniques et Cultures, 9 (n.s.):105-140.

FAUSTO, Carlos. 2008. "Donos demais: maestria e domínio na Amazônia". Mana, 14(2):329-366. 
FEARNSIDE, Philip. 1989. A ocupação humana de Rondônia: impactos, limites e planejamento. Brasília: Programa Polonoroeste/SCT-PR/CNPq (Relatório de Pesquisa n. 5).

GORDILLO, Gastón. 2006. “¡Formas modernas de caza y recoleción?” In: En el Gran Chaco: antropologías y historias. Buenos Aires: Prometeo Libros. pp. 277-296.

GORDON, Cesar. 2006. Economia selvagem: ritual e mercadoria entre os índios Xikrin-Mebêngôkre. São Paulo: Editora da UNESP/ISA; Rio de Janeiro: NuTI.

GUERRA, Emerson. 2008. Organização política e segurança alimentar na sociedade Krahô. Uberlândia: Edufu.

HECHT, Susanna. 1993. "The logic of livestock and deforestation in Amazonia". BioScience, 43(10):687-695.

INGLEZ DE SOUZA, Cássio. 2008. “Etnodesenvolvimento”. In: FábioVaz Ribeiro de Almeida (org.), Guia para a formação em gestão de projetos indígenas. PDPI. Brasília: Paralelo 15/Esplanada dos Ministérios.

KELLY, José Antonio. 2005. “Notas para uma teoria do “virar branco”. Mana, 11(1):201-234.

LANDIN, David. 1983. Dicionário e léxico Karitiana/Português. Brasília: SIL.

LEITE, Maurício. 2007. Transformação e persistência: antropologia da alimentação e nutrição em uma sociedade indígena amazônica. Rio de Janeiro: Editora da Fiocruz.

MACDONALD, Theodore. 1997. De cazadores a ganaderos. Quito: Abya-Yala.

MARANHÃO, Renata. 2003. Relatório de levantamento ambiental da Terra Indígena Karitiana. Brasília: Funai (inédito).

MINDLIN, Betty \& LEONEL Jr., Mauro. 1983. Relatório de avaliação da situação da comunidade Karitiana. Ministério do Interior - SUDECO/FIPE (inédito).

PIKETTY, M.-G.; BASTOS DA VEIGA, J.; TORRAND, J.-F.; ALVES, A.; POCCARDCHAPUIS, R.; THALES, M.; HOSTIOU, N. \& VENTURIERI, A. 2004. "Por que a pecuária está avançando na Amazônia Oriental?”. In: D. Sayago; J.-F. Tourrand \& M. Bursztyn (orgs.), Amazônia: cenas e cenários. Brasília: Editora da UnB.

PIMENTEL, Sidney. 1997. O chão é o limite: a festa do peão de boiadeiro e a domesticação do sertão. Goiânia: Editora da UFG.

RIVIÈRE, Peter. 1972. The forgotten frontier: ranchers of North Brazil. New York: Holt, Rinehart and Winston.

SALGADO, Carlos Bezerra. 2005. Segurança alimentar em terras indígenas: os Shanenawá no rio Envira - Acre. Dissertação de mestrado, Universidade Federal do Acre.

2007. "Segurança alimentar e nutricional em terras indígenas". Revista de Estudos e Pesquisas (Funai), 4(1):131-186. 
SCHRÖDER, Peter. 2003. Economia indígena: situação atual e problemas relacionados a projetos indígenas de comercialização na Amazônia Legal. Recife: Editora Universitária da UFPE.

SMERALDI, Roberto \& MAY, Peter. 2008. O reino do gado: uma nova fase na pecuarização da Amazônia. São Paulo: Amigos da Terra - Amazônia Brasileira.

2009. A hora da conta: pecuária, Amazônia e conjuntura. São Paulo: Amigos da Terra - Amazônia Brasileira.

STORTO, Luciana. 1996. Livro de apoio ao aprendizado da ortografia Karitiana. Mimeo. (inédito).

TAUSSIG, Michael. 1993. Xamanismo, colonialismo e o homem selvagem: um estudo sobre o poder e a cura. São Paulo: Paz \& Terra.

TONI, F.; CARVALHO DOS SANTOS, J.; SANT'ANA DE MENEZES, R.; WOOD, C. \& SANT’ANA, H. 2007. Expansão e trajetórias da pecuária na Amazônia: Acre, Brasil. Brasília: Ed. da UnB.

VANDER VELDEN, Felipe. 2004. Por onde o sangue circula: os Karitiana e a intervenção biomédica. Dissertação de mestrado, Unicamp.

. 2008. “O gosto dos outros: o sal e a transformação dos corpos entre os Karitiana no sudoeste da Amazônia”. Temáticas, 16(31-32):13-49.

2010. Inquietas companhias: sobre os animais de criação entre os Karitiana. Tese de doutorado, Unicamp.

. 2010b. “De volta para o passado: territorialização e 'contraterritorialização' na história karitiana”. Sociedade e Cultura, v.13:55-65.

VILAÇA, Aparecida. 2000. “O que significa tornar-se outro? Xamanismo e contato interétnico na Amazônia”. Revista Brasileira de Ciências Sociais, 15(44):59-72. 


\section{Resumo}

Projetos de criação animal vem sendo defendidos como uma das formas de solucionar problemas como a carência alimentar e a falta de alternativas econômicas nas aldeias indígenas na Amazônia. Contudo, o exemplo dos Karitiana - povo de língua Tupi-Arikém no sudoeste da Amazônia brasileira - aqui discutido aponta para as múltiplas razões que podem estar envolvidas no desejo que vários grupos indígenas manifestam por ter gado bovino e projetos de criação animal. Argumento que é, sobretudo, a vontade de ser 'fazendeiro' que comanda a intenção de constituir rebanhos e, assim sendo, os bois acabam por não ser utilizados para a alimentação humana.

Palavras-chave: gado - criação animal Karitiana - Amazônia - projetos.

\section{Abstract}

Animal husbandry projects have been proposed as a way to solve food shortage and lack of economic alternatives in indigenous villages in the Amazon. This paper, however, discusses the case of the Karitana, a Tupi-Arikém speaking people in southwestern Brazilian Amazonia. This example points to multiple reasons that may be involved in the Amerindian's desire for cattle and husbandry projects. I argue that it is above all the desire to be a 'rancher' (as landholder and a cattleman) that motivates the desire for owning herds, and thus cattle are in the end not used as a resource for human nourishment.

Keywords: cattle - animal husbandry Karitiana - Amazon - projects. 